\title{
Rectal Cancer Metastasizing to Breast: A Case Report and Review of Literature
}

\author{
Soha Yahya Hejazi ${ }^{*}$, Fahad Ali Alghamdi², Nisar Haider Zaidi ${ }^{1}$ \\ ${ }^{1}$ Department of Surgery, Faculty of Medicine, King Abdulaziz University Hospital, King Abdulaziz University, \\ Jeddah, Saudi Arabia \\ ${ }^{2}$ Department of Pathology, Faculty of Medicine, King Abdulaziz University Hospital, King Abdulaziz University, \\ Jeddah, Saudi Arabia \\ Email: "hejazisoha1423@gmail.com, Fahad.algh@gmail.com,drnhzaidi@hotmail.com
}

Received 10 December 2015; accepted 15 February 2016; published 18 February 2016

Copyright (C) 2016 by authors and Scientific Research Publishing Inc.

This work is licensed under the Creative Commons Attribution International License (CC BY).

http://creativecommons.org/licenses/by/4.0/

(c) (i) Open Access

\begin{abstract}
Objectives: To report rare metastasis in breast from rectal cancer. Case Report: A 47-year-old married lady who presented with rectal bleeding for six weeks and diagnosed as a case of adenocarcinoma with no metastasis underwent neoadjuvent radiotherapy and chemotherapy and then abdominoperineal resection on follow-up found to have left breast mass and skin lesion in upper abdominal wall. Mammogram showed BIRADS-5. Tru cut biopsy showed mucinous/signet ring adenocarcinoma and she underwent lumpectomy and sentinel lymph node biopsy and excision of skin lesion. Histopathology of breast lump and skin lesion came as mucinous adeno-carcinoma of colonic origin, but all axillary lymph nodes were negative for malignancy. Conclusion: Metastatic breast lump is rare entity and every effort to be put to diagnose it using modern diagnostic tools.
\end{abstract}

\section{Keywords}

Metastasis to Breast, Rectal Cancer, Mucinous Adenoacrcinoma

\section{Introduction}

Primary breast cancer is the most common malignancy in females. Metastasis from breast to other organs is common but metastasis to breast is extremely rare and accounts for $0.43 \%$ of all breast malignancies [1]. The most common malignancies which metastasize to breast are melanoma, sarcoma, lymphoma, lung carcinoma, prostate and ovarian tumors [2] [3]. The most common tumor which metastasizes to breast is malignant melanoma [4] [5]. Gastrointestinal carcinoids have also been reported to have metastatisize to breast [6] [7]. Metasta-

"Corresponding author. 
sis to breast from colon cancer is extremely rare and only 20 cases have been reported in literature [8]. We present a case of colonic adenocarcinoma, which after undergoing abdominoperineal resection and radiotherapy and chemotherapy, metastasized to breast.

\section{Case Report}

47-year-old married lady who is not known to have any medical illness presented to surgical clinic in March 2011 with history of bleeding per rectum for six weeks duration. Digital rectal examination showed low circumferential mass with bleeding streaks. Colonoscopy did not reveal any other lesion in colon. Biopsy showed adenocarcinoma with cells having signet ring morphology and abundant extra-cellular mucin in more than $50 \%$ of the biopsy (mucinous adenocarcinoma) [Pathology Figure 1(a), Pathology Figure 1(b)]. Computerized tomography (CT) scan of chest and abdomen showed no evidence of metastasis. Initial CEA was 0.368 [normal range $0-3.4 \mathrm{ng} / \mathrm{ml}$ ]. She was given neoadjuvent radiation therapy [26 cycles] and xeloda. She did not get response to chemotherapy and her tumor was increased in size with circumferential extension but there was no metastasis yet. She was diagnosed as a case of cancer rectum and underwent APR in July 2011. Histopathology showed rectal adenocarcinoma [4 $\times 4 \times 3 \mathrm{~cm}$ ] with acellular mucinous changes [Pathology Figure 2], 27/27 LN were involved by tumor. Both proximal and distal margins were free. She got adjuvant radiotherapy and chemotherapy [folfox].

She was in regular follow-up with CT chest, abdomen and pelvis and colonoscopy. Three years later, CT of chest showed suspicious mass in her breast. She had no complaints of breast mass before nor had she family history of breast cancer. Breast examination revealed ill-defined mass in left breast at supero-lateral quadrant with no nipple areola changes. Right breast and both axilla were normal. Ultrasound [Figure 1] and Mammogram breast [Figure 2, Figure 3] showed BIRADS-5, left breast mass $1.7 \times 1.6 \mathrm{~cm}$ with speculation and hypervascularity with multiple abnormal looking left axillary lymph nodes. Tru cut biopsy of breast mass showed mucinous adenocarcinoma with signet ring morphology and extra-cellular mucin with similar morphology of previous colonic lesion. Immunohistochemistry confirmed its colonic origin with metastatic to breast (i.e. tumor cells were positive for cytokeratin 20 and CDX-2 immunomarkers [Pathology Figures 3(a)-(c)] and negative for ER and PR immune-markers [not shown]). CT scan of chest, abdomen, pelvis and bone showed no more metastasis. The case was discussed in our tumor board and the opinion of oncologist based on diffuse body MRI (PET scan not available in our institution) was to go for surgical excision for single site metastasis and no need for chemotherapy. The surgical option was discussed with patient and she agreed for surgical excision with wide local excision with excision of skin lesion and sentinel lymph node biopsy (for academic purposes) and patient signed consent and was operated on 31-12-2014. Histopathology showed metastatic mucinous adenocarcinoma with signet ring morphology in breast as well as in skin lesion. Axillary lymph nodes were all negative for malignancy. She was discharged home and followed up in OPD. Few months later in March 2015 she presented with picture of small bowel obstruction with hypovolemia and decreased urine out put. CT scan abdomen



(a)

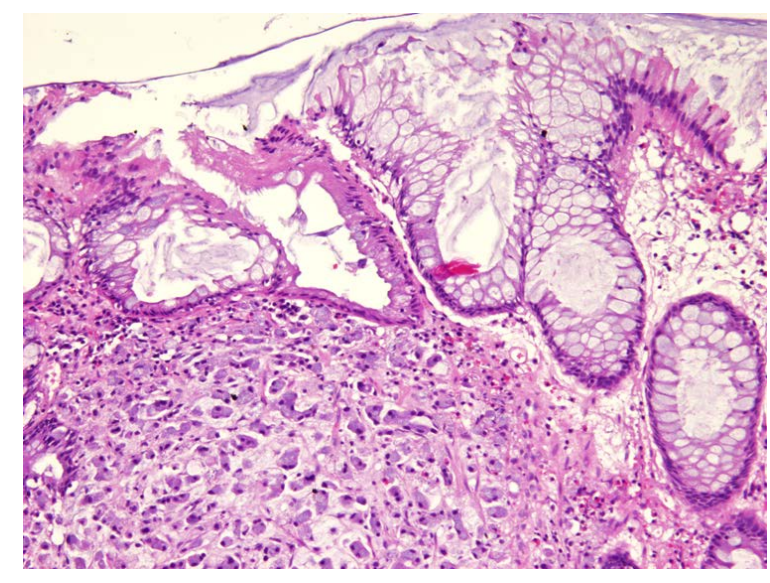

(b)

Pathology Figure 1. (a) Low power (4×); infiltrating adenocarcinoma (right) and some residual normal colonic mucosa (left); (b) High power (20×); infiltrating tumor (left) with signet ring morphology and extra-cellular mucin. 


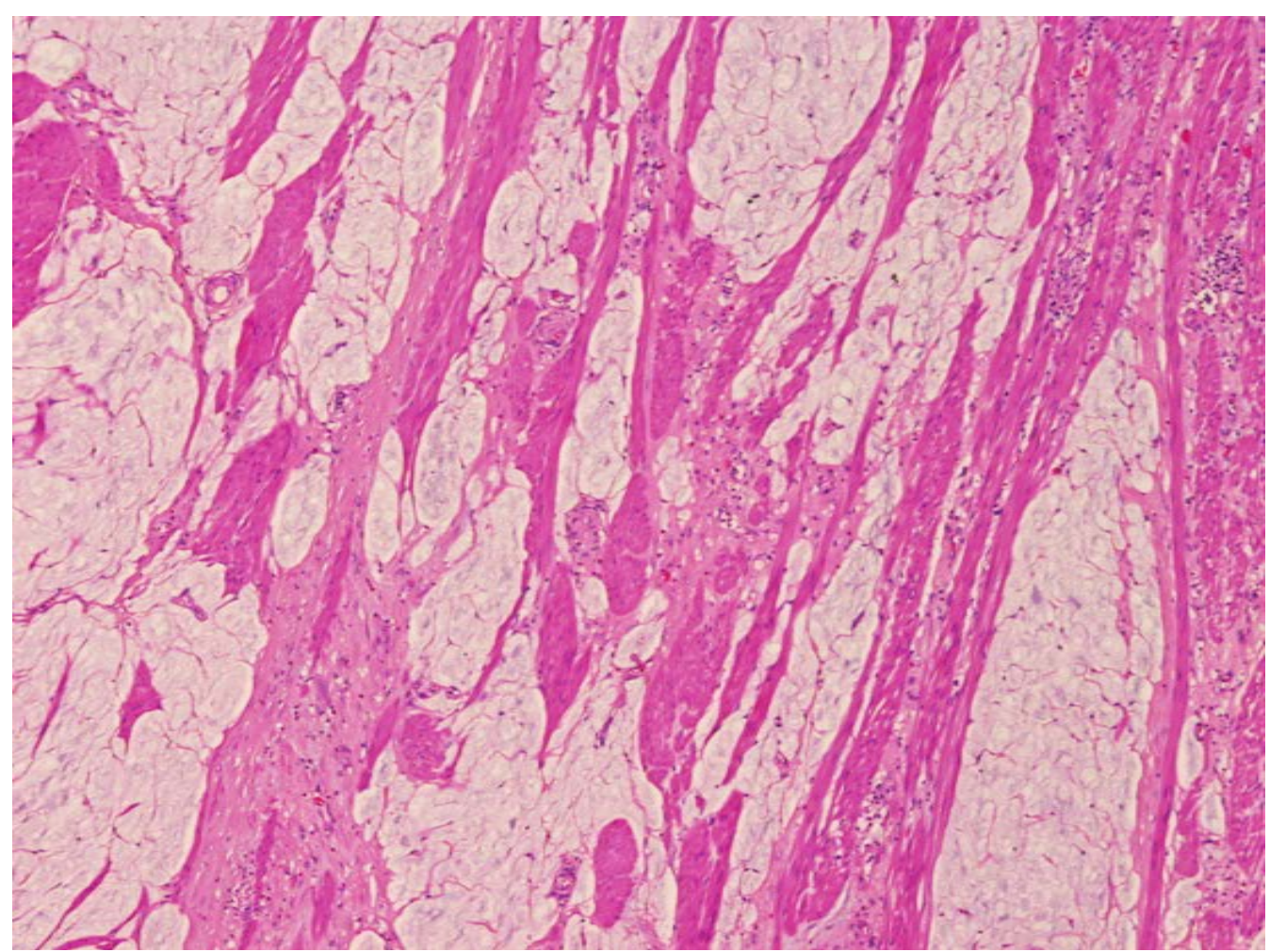

Pathology Figure 2. Post neo-adjuvant; dissecting mucin between normal connective tissue.

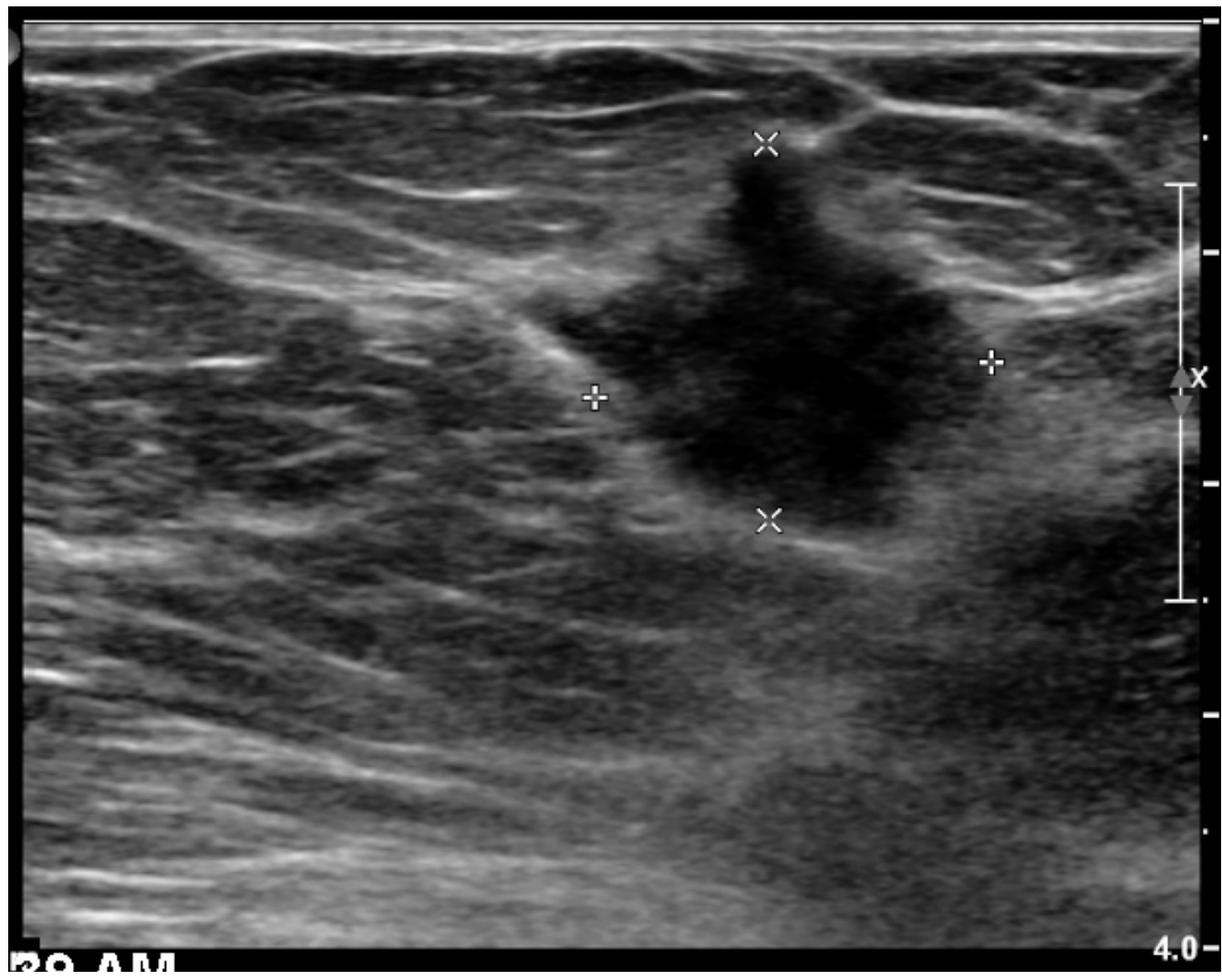

Figure 1. Ultrasound left breast showing mass in supero-lateral quadrant. 


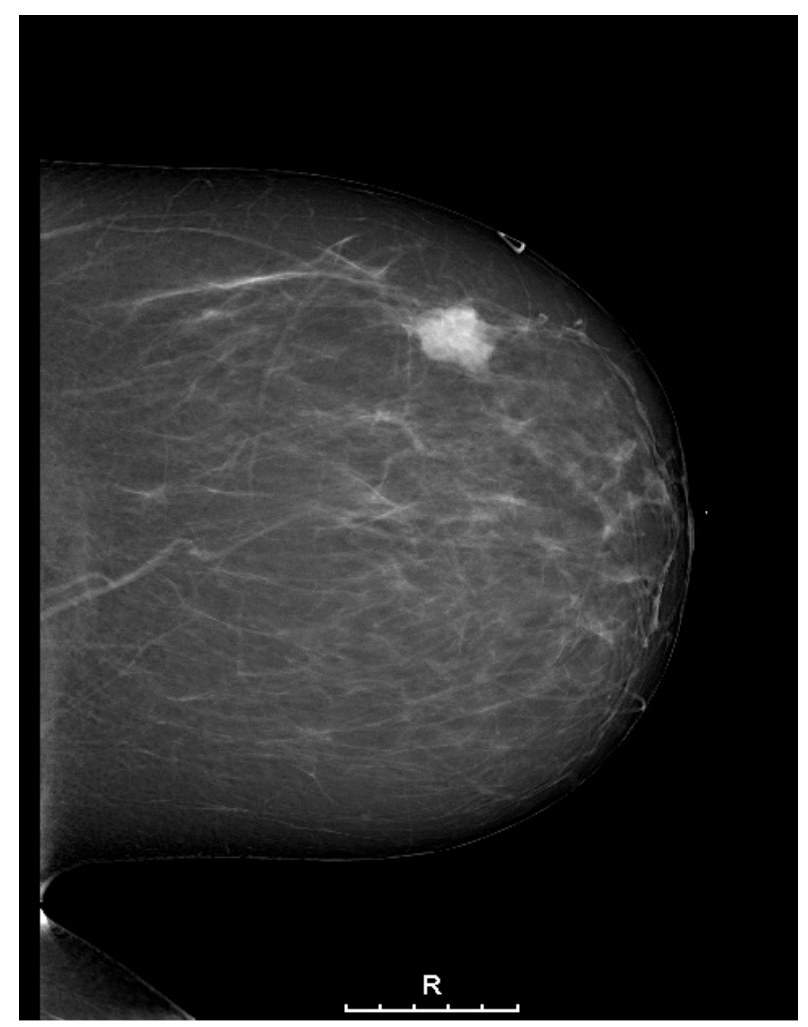

Figure 2. Mammogram left breast showing mass in supero-lateral quadrant.

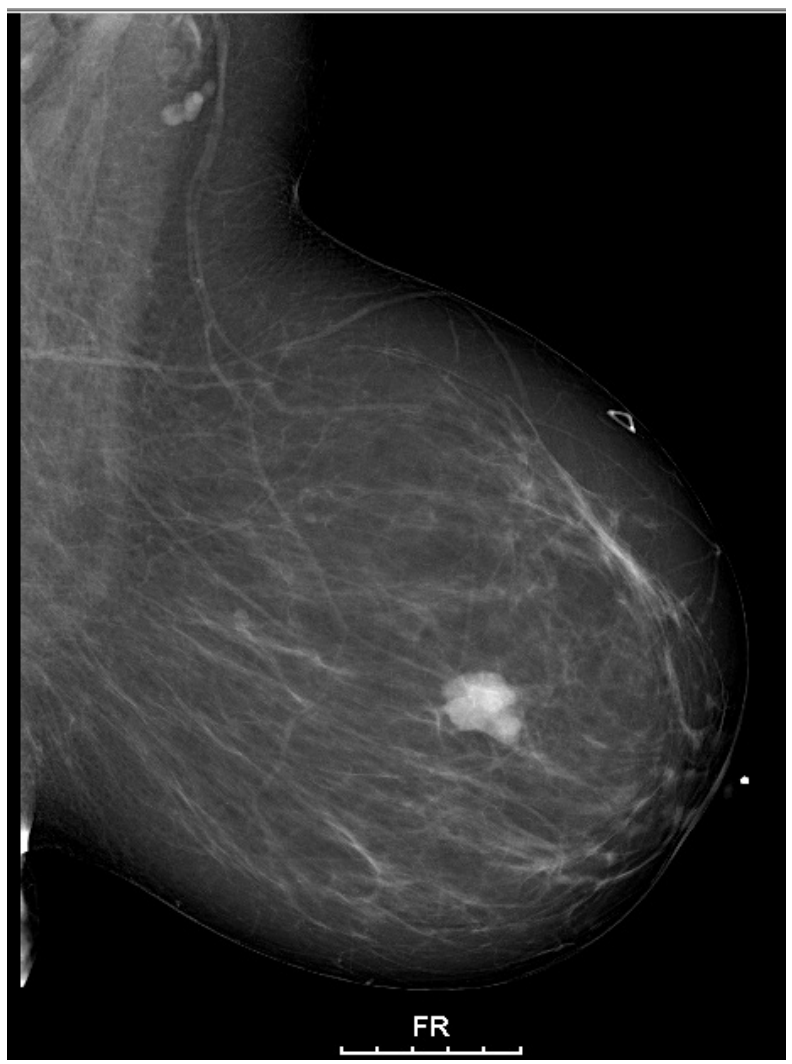

Figure 3. Mammogram left breast showing mass in supero-lateral quadrant. 


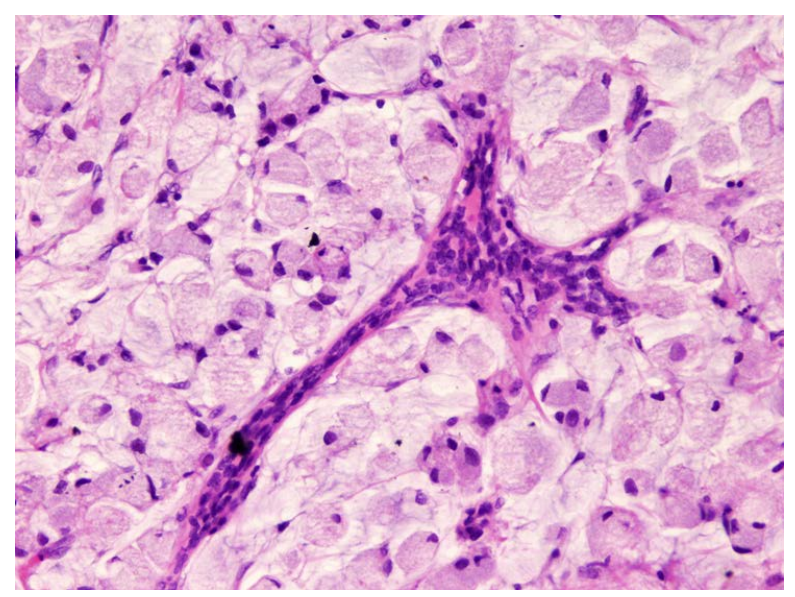

(a)

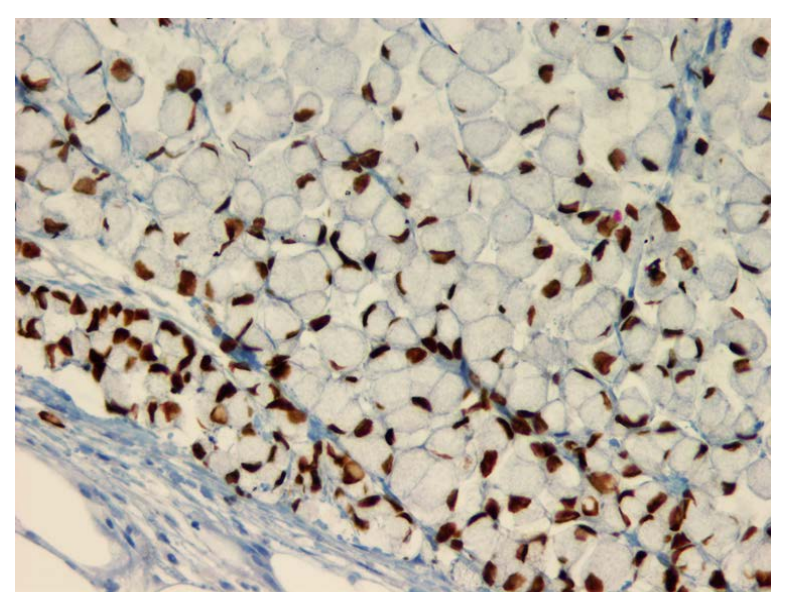

(b)

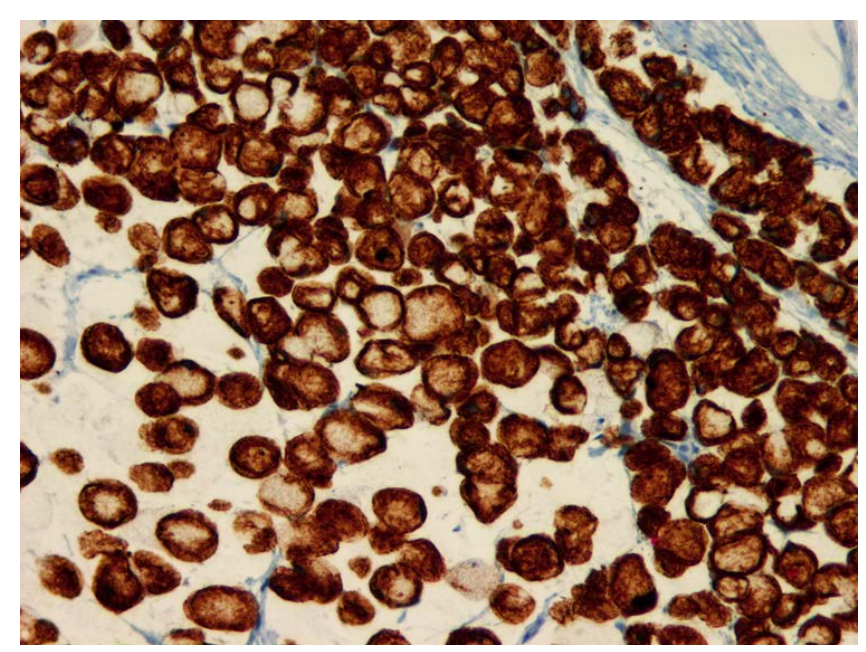

(c)

Pathology Figure 3. (a) Breast duct in center surrounded by signet ring cells and extra-cellular mucin; (b) Cytokertin 20 immunomarker (membranous and cytoplasmic staining); (c) CDX-2 immunomarker (nuclear staining).

showed multiple internal iliac lymph nodes, compressing right ureter causing right hydroureter and hydronephrosis and transitional zone in small bowel obstruction in distal ileal loopsdue to soft tissue lesion in mesentry. Patient was prepared for operation, intravenous antibiotics given, rehydration and prophylactic clexan was given. Right ureteral stent was placed by urologist, exploratory laparotomy was done, two sites of small bowel obstruction were found, first $10 \mathrm{~cm}$ proximal to ileocecal valve and other $10 \mathrm{~cm}$ proximal to it. Resection of the segment done and proximal end ileostomy done and distal loop was brought out as mucus fistula. There were multiple intraperitoneal metastasis involving abdominal wall, urinary bladderand uterus. Sister Mary Joseph nodule was found and was excised and sent for histopathology. Complete excision of mesenteric mass was not possible due to severe adhesions. Second day post op patient developed right lower limb deep vein thrombosis. CT angiography done which was negative for pulmonary embolism. Patient was shifted to warfarin. Histopathology showed metastatic signet ring adenocarcinoma with extensive extracellular mucin which is similar to histopathology of breast lesion. Patient was evaluated by oncologist and put on "Folferi" regime as out patient after IVC filter was placed in April 2015. Four cycles of chemotherapy could not be completed as patient developed septic shock due to urosepsis.

Later patient presented with fever, right flank pain and decreased urine out put. She was diagnosed as urosepsis due to infected and occluded right ureteric stent so right ureteric stent was changed. There was development of left hydroureter and hydronephrosis and left DJ sent was also placed. Patient gradually deteriorated and admitted to Intensive care unit as septic shock. She died in 17-11-2015 due to septic shock. 


\section{Discussion}

Most common metastasis in the breast is from contralateral breast carcinoma. Colon cancer metastasize to lymph nodes, live, lungs, adrenals, ovaries and bones, in that order. There are several features of metastasis to breast like location of lump in fat or subcutaneous tissue, lack of microcalcification in mammogram and lack of insitu disease in histopathology of lump [9] [10]. Treatment of primary is paramount in the overall survival of the patient. More than $90 \%$ of cancer deaths are caused by metastasis [11]. After a lot of research, it has been established that metastasis is the result of multiple interrelated steps in which cancer cells must be separated from the primary tumor, intravasate into the circulatory and lymphatic systems, evade immune attack, extravasate at distant capillary beds, and invade and proliferate in distant organs [12].

Laparoscopic colon surgery is known cause of skin metastasis [13]. In a study of 19 cases of breast metastasis from colon, 3 of the 19 patients presented synchronously, while the rest presented at median 15 months after diagnosis of colon cancer, lymph node involvement in 5 of 10 cases with median follow-up of 15 months, 5 died at the last follow-up [14]. The incidence of breast metastasis at the same time of detection of colon cancer is low, with only three cases reported so far [15]. Incidence of breast metastasis from colon in autopsy series is $6.6 \%$ to $7 \%$ [16]. Incidence of breast metastasis from extramammary site in clinical series is $1.2 \%$ to $2 \%$ while $1.7 \%$ to $6.6 \%$ in autopsy series [17]. Clinically metastatic breast lumps grow rapidly, most commonly in the upper outer quadrant of the breast [18] [19]. These lumps do not cause skin changes, nipple retraction, or nipple discharge [20] [21]. Metastatic breast lump due to colon cancer is Cytokeratin 7 negative and cytokeratin 20 positive while majority of primary breast cancers are CK7 positive and CK20 negative [22]. CDX2 is highly sensitive and specific for colonic cancers [23]. In addition, estrogen and progesterone receptors are usually negative in metastatic breast cancers. Survival from time of diagnosis of metastasis to breast is less than 12 months [24]. Barthelmes et al. advocated that surgical excision should be avoided in the view of short life expectancy and risk of seeding to the skin [25]. In our case we went for excision of breast lump despite of known short life expectancy of these patients, but due to urological problem of hydronephrosis in both kidneys patient developed urosepsis and died.

\section{Conclusion}

Metastatic breast lump is rare entity and every effort to be put to diagnose it using modern diagnostic tools.

\section{References}

[1] Georgiannos, S.N., Chin, J., Goode, A.W. and Sheaff, M. (2001) Secondary Neoplasms of the Breast: A Survey of the 20th Century. Cancer, 92, 2259-2266. http://dx.doi.org/10.1002/1097-0142(20011101)92:9<2259::AID-CNCR1571>3.0.CO;2-O

[2] Williams, S.A., Ehlers 2nd, R.A., Hunt, K.K., Yi, M., Kuerer, H.M., Singletary, S.E., et al. (2007) Metastases to the Breast from Nonbreast Solid Neoplasms: Presentation and Determinants of Survival. Cancer, 110, 731-737. http://dx.doi.org/10.1002/cncr.22835

[3] Vizcaíno, I., Torregrosa, A., Higueras, V., Morote, V., Cremades, A., Torres, V., et al. (2001) Metastasis to the Breast from Extramammary Malignancies: A Report of Four Cases and a Review of Literature. European Radiology, 11, 1659-1665. http://dx.doi.org/10.1007/s003300000807

[4] Nielson, M., Anderson, J.A., Henriksen, F.W., et al. (1981) Metastasis to the Breast from Extramammary Carcinoma. Acta pathologica et microbiologica Scandinavica. Section A, 89, 251-256.

[5] Piatelli, A. (1990) Lingual Metastasis from Carcinoma of Colon: A Case Report and Review of the Literature. Acta Stomatologica Belgica, 87, 257-264.

[6] Schurch, W., Lamoureux, E., Lefebvre, R. and Fauleux, J.P. (1980) Solitary Breast Metastasis: First Manifestation of an Occult Carcinoid of the Ileum. Virchows Archiv A, Pathological Anatomy and Histology, 386, 117-124. http://dx.doi.org/10.1007/BF00432649

[7] Chodorff, R.J. (1965) Solitary Breast Metastasis from Carcinoid of the Ileum. American Journal of Surgery, 109, 814815. http://dx.doi.org/10.1016/S0002-9610(65)80059-9

[8] Barthelmes, L., Simpson, J.S., Douglas-Jones, A.G. and Sweetland, H.M. (2010) Metastasis of Primary Colon Cancer to the Breast-Leave Well Alone. Breast Care, 5, 23-25. http://dx.doi.org/10.1159/000272303

[9] Harvey, E.B. and Brinton, I.A. (1985) Second Cancer Following Cancer of Breast in Connecticut 1935-82. National Cancer Institute Monograph, 68, 99-112.

[10] Lewison, E.F. and Neto, A.S. (1971) Bilateral Breast Cancer at Johns Hopkins Hospital. A Discussion of Dilemma of 
Contralateral Breast Cancer. Cancer, 28, 1297-1301.

http://dx.doi.org/10.1002/1097-0142(1971)28:5<1297::AID-CNCR2820280532>3.0.CO;2-5

[11] Chaffer, C.L. and Weinberg, R.A. (2011) A Perspective on Cancer Cell Metastasis. Science, 331, 1559-1564. http://dx.doi.org/10.1126/science.1203543

[12] Chambers, A.F., Groom, A.C. and MacDonald, I.C. (2002) Dissemination and Growth of Cancer Cells in Metastatic Sites. Nature Reviews Cancer, 2, 563-572. http://dx.doi.org/10.1038/nrc865

[13] Curte, M.J. (2004) Port Site Metastases. The American Journal of Surgery, 187, 705-712. http://dx.doi.org/10.1016/j.amjsurg.2003.10.015

[14] Barthelmesa, L., Simpsona, J.S., Douglas-Jone, A.G. and Sweetland, H.M. (2010) Breast Care Metastasis of Primary Colon Cancer to the Breast-Leave Well Alone. Breast Care, 5, 23-25. http://dx.doi.org/10.1159/000272303

[15] Shackelford, R.E., Allam-Nandyala, P., Bui, M.M., Kiluk, J.V. and Esposito, N.N. (2011) Primary Colorectal Adenocarcinoma Metastatic to the Breast: Case Report and Review of Nineteen Cases. Case Reports in Medicine, 2011, Article ID: 738413. http://dx.doi.org/10.1155/2011/738413

[16] Sanchez, L.D., Chelliah, T., Meisher, I. and Niranjan, S. (2008) Rare Case of Breast Tumor Secondary to Rectal Adenocarcinoma. Southern Medical Journal, 101, 1062-1064. http://dx.doi.org/10.1097/SMJ.0b013e318183d071

[17] Alva, S. and Shetty-Alva, N. (1999) An Update of Tumor Metastasis to the Breast Data. Archives of Surgery, $134,450$. http://dx.doi.org/10.1001/archsurg.134.4.450

[18] Lal, R.L. and Joffe, J.K. (1999) Rectal Carcinoma Metastatic to the Breast. Clinical Oncology, 11, 422-423. http://dx.doi.org/10.1053/clon.1999.9098

[19] Fernández de Bobadilla, L., García Villanueva, A., Collado, M., et al. (2004) Breast Metastasis of Primary Colon Cancer. Revista Espanola de Enfermedades Digestives, 96, 415-419. http://dx.doi.org/10.4321/S1130-01082004000600007

[20] Vergier, B., Trojani, M., de Mascarel, I., Coindre, J.M. and Le Treut, A. (1991) Metastases to the Breast: Differential Diagnosis from Primary Breast Carcinoma. Journal of Surgical Oncology, 48, 112-116. http://dx.doi.org/10.1002/jso.2930480208

[21] Hajdu, S.I. and Urban, J.A. (1972) Cancers Metastatic to the Breast. Cancer, 29, 1691-1696. http://dx.doi.org/10.1002/1097-0142(197206)29:6<1691::AID-CNCR2820290637>3.0.CO;2-4

[22] Noh, K.T., Oh, B., Sung, S.H., et al. (2011) Metastasis to the Breast from Colonic Adenocarcinoma. Journal of the Korean Surgical Society, 81, S43-S46. http://dx.doi.org/10.4174/jkss.2011.81.Suppl1.S43

[23] Cabibi, D., Cipolla, C., Valerio, M.R. and Ingrao, S. (2011) Metastatic Seeding of Colon Adenocarcinoma Manifesting as Synchronous Breast and Chest Wall Localization: Report of a Case. Surgery Today, 41, 242-246. http://dx.doi.org/10.1007/s00595-009-4222-3

[24] Perin, T., Canzonieri, V., Memeo, L. and Massarut, S. (2011) Breast Metastasis of Primary Colon Cancer with Micrometastasis in the Axillary Sentinel Node: A Metastasis That Metastasized? Diagnostic Pathology, 6, 45. http://dx.doi.org/10.1186/1746-1596-6-45

[25] Barthelmes, L., Simpson, J.S., Douglas-Jones, A.G. and Sweetland, H.M. (2010) Metastasis of Primary Colon Cancer to the Breast-Leave Well Alone. Breast Care, 5, 23-25. http://dx.doi.org/10.1159/000272303 